\title{
PENINGKATAN HASIL BELAJAR GERAK DASAR PERMAINAN KIPPERS MELALUI MODIFIKASI ALAT PEMBELAJARAN
}

\author{
Irsan Rifai ${ }^{(1)}$ Agus Kristiyanto ${ }^{(2)}$ \\ ${ }^{(1)(2)}$ Universitas Sebelas Maret Surakarta
}

\begin{abstract}
The purpose of this research was to improve the study result of basic movement in kippers on students in class $4 B$ Bratan 1 State Elementary School No.71 Surakarta school year 2016/2017.

This research was a Class Action Research. This research was done in two cycles, with each cycle contains planning, implementation, observation, and reflection. The subjects of this research were 36 students in class $4 B$ Bratan 1 State Elementary School No.71 Surakarta. The sources of data were from teachers, students, and researchers. The techniques of collecting data were observation, test. The validity of the data used data triangle technique. The technique of analyzing the data used descriptive technique which based on the quantitative analysis with percentage.

From the analysis, the result obtained from pre-cycle to cycle I and from cycle I to cycle II. This was observed from the study result of the students on precycle. From 36 students, it was only 12 students who passed and 24 students who failed or with percentage 33,3\% of students who pass and 66,7\% of students who failed. Then the study result which was shown by students from cycle I showed the improvement of 20 students or 55,6\% who passed and 16 students or 44,4\% who failed. In cycle II, the improvement of the study result was $86,1 \%$ or 31 students who passed and 13,9\% or 5 students who failed.

The conclusion of this research was using the modification of education tool could improve the study result of basic movement in kippers game on students in class $4 B$ Bratan 1 State Elementary School No.71 Surakarta school year $2016 / 2017$.
\end{abstract}

Keywords: Basic movement, study result, education tool modification 
PENDAHULUAN

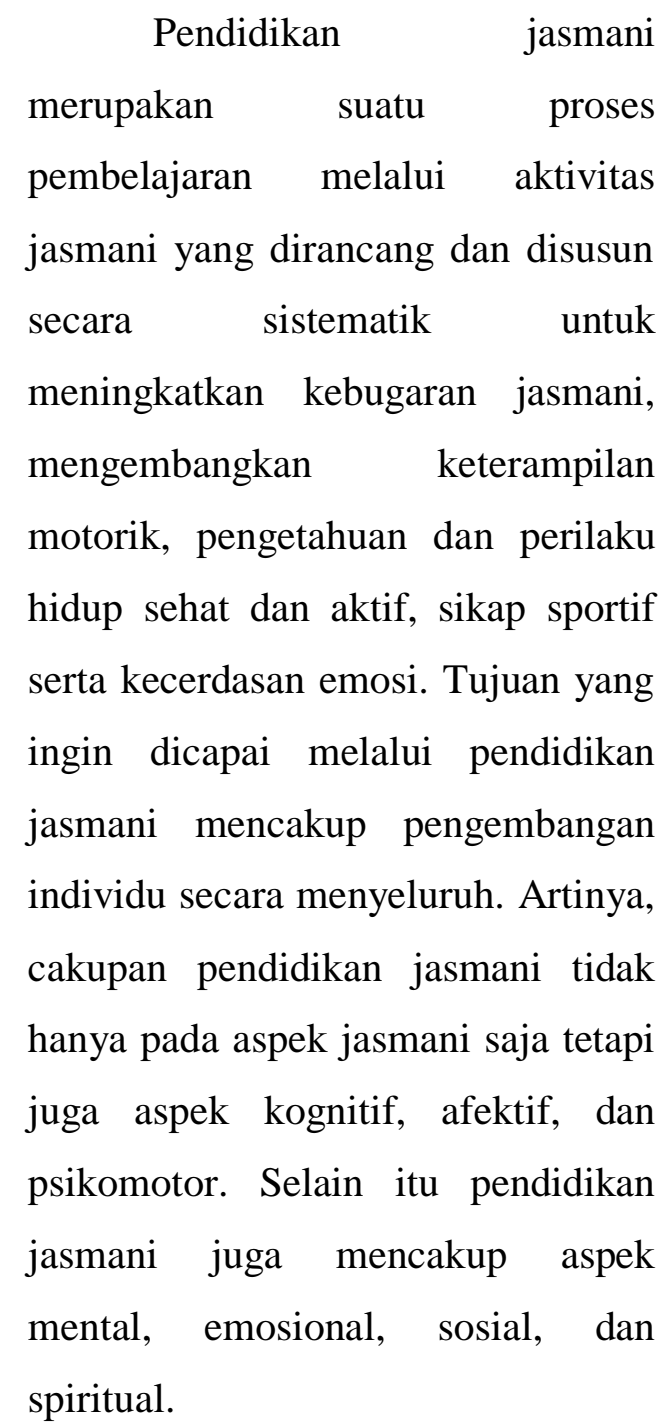

Menurut Departemen

Pendidikan Nasional (2007: 1),

Pendidikan Jasmani Olahraga dan

Kesehatan (Penjasorkes) di sekolah

merupakan bagian integral dari

pendidikan secara keseluruhan,

bertujuan untuk menegembangkan

aspek kebugaran jasmani,

keterampilan gerak, keterampilan

berpikir kritis, keterampilan sosial, penalaran, stabilitas emosioanal, tindakan moral, aspek pola hidup sehat dan pengenalan lingkungan bersih melalui aktivitas jasmani, olahraga dan kesehatan terpilih yang direncanakan secara sistematis dalam rangka mencapai tujuan pendidikan nasional. Pendidikan Jasmani Olahraga dan Kesehatan (Penjasorkes) di sekolah merupakan bagian integral dari pendidikan secara keseluruhan. Oleh karena itu, sudah selayaknya bila diberikan perhatian yang proporsional.Sejalan dengan hal tersebut, Pendidikan Jasmani Olahraga dan Kesehatan di sekolah seharusnya dilaksanakan secara efisien, efektif serta disesuaikan dengan kondisi fisik dan psikis anak.

Penjasorkes yang diajarkan di Sekolah Dasar memiliki peranan yang sangat penting, karena sebagai suatu proses pembinaan anak sejak usia dini, yaitu memberi kesempatan kepada anak untuk terlibat secara langsung dalam berbagai pengalaman belajar melalui aktivitas jasmani, olahraga dan kesehatan yang terpilih dilakukan secara sistematis. Pembekalan pengalaman 
belajar itu diarahkan untuk membina pertumbuhan fisik dan pengembangan psikis yang lebih baik, sekaligus membentuk pola hidup sehat dan bugar (Munarwan, 2010: 12).

Salah satu tujuan pelaksanaan Pendidikan Jasmani, Olahraga dan Kesehatan di Sekolah Dasar yang tercantum dalam Badan Standar Nasional Pendidikan (2006: 703), adalah meningkatkan kemampuan dan keterampilan gerak dasar. Keterampilan gerak adalah suatu kemampuan yang penting dalam pendidikan jasmani bahkan dalam kehidupan sehari-hari. Salah satu program pendidikan jasmani adalah agar siswa terampil dalam beraktivitas jasmani. Keterampilan gerak yang diperoleh melalui pendidikan jasmani tidak hanya berguna untuk menguasai cabang olahraga tertentu saja tapi juga untuk melakukan aktivitas dan tugas fisik dalam kehidupan sehari-hari.

Gerak dasar merupakan gerak yang bersifat umum, apabila dapat dikuasai oleh siswa sekolah dasar akan menjadi landasan untuk dapat mengembangkan gerak-gerak yang lebih kompleks. Gerak dasar itu sendiri dibagi menjadi tiga, yaitu lokomotor, non lokomotor.

Gerak dasar lokomotor merupakan gerak yang dilakukan dari satu tempat ke tempat lain atau bisa juga disebut gerak berpindah tempat. Gerak dasar non lokomotor merupakan gerak yang dilakukan di tempat (tidak berpindah tempat). Sementara itu gerak dasar merupakan gerak untuk bertindak melakukan bentuk gerak dari anggota badanya secara lebih terampil atau gerak yang berhubungan dengan penggunakan alat. Pentingnya penguasaan gerak dasar bagi siswa sekolah Dasar harus mendapatkan perhatian dari guru Pendidikan Jasmani. Seorang guru Pendidikan Jasmani Olahraga dan Kesehatan harus mampu memberikan stimulasi atau mengembangkan gerak dasar siswa dengan aktivitas yang menarik dan mudah dilakukan oleh siswa.

Sekolah Dasar pembelajaran Penjasorkes berisi materi-materi yang dapat dikelompokan menjadi aktivitas pengembangan, senam, aktivitas ritmik, akuatik, pendidikan luar kelas, permainan dan olahraga. 
Sebagai contoh, terdapat standar kompetensi "Mempraktikkan gerak dasar ke dalam permainan dan olahraga dan nilai-nilai yang terkandung di dalamnya". Dengan Kompetensi Dasar "Mempraktikkan gerak dasar berbagai gerakan yang bervariasi dalam permainan bola kecil beregu dengan peraturan yang dimodifikasi, serta nilai kerjasama, sportivitas dan kejujuran". Pembelajaran penjasorkes melibatkan semua ranah pendidikan baik afektif (sikap), psikomotor (keterampilan fisik), maupun kognitif (konsep).

Kurikulum dalam mata pelajaran Penjasorkes di Sekolah dasar, salah satunya terdapat materi permainan dan olahraga. Materi permainan dan olahraga meliputi: Olahraga tradisional, permainan, eksplorasi gerak, keterampilan lokomotor dan non-lokomotor, dan , atletik, kippers, rounders, kasti, sepak bola, bola basket, bola voli, tenis meja, tenis lapangan, bulu tangkis, dan bela diri serta aktivitas lainya.

$\begin{array}{clc}\text { Sesuai } & \text { ruang lingkup } \\ \text { tersebut, dapat diketahui bahwa }\end{array}$ permainan bola kecil merupakan salah satu bagian dari pembelajaran pendidikan di Sekolah Dasar. Permainan bola kecil merupakan permainan yang memakai bola kecil, seperti kippers, kasti, bola bakar, bulu tangkis, tenis dan lain sebagainya.

SD Negeri Bratan 1 No.71 Kota Surakarta merupakan Sekolah Dasar yang menggunakan permainan kippers sebagai materi permainan bola kecil pada mata pelajaran Penjasorkes. Namun pelaksanaan permainan kippers SD Negeri Bratan 1 No.71 Kota Surakarta masih mengalami banyak kendala seperti alat yang seadanya sehingga pembelajaran menjadi kurang maksimal bahkan jarang sekali permainan kippers diajarkan dalam pembelajaran. Kondisi tersebut mengakibatkan siswa kurang terampil dalam hal gerak dasar permainan kippers, seperti melempar, menangkap, memukul dan juga dalam hal permainan secara keseluruhan. Selain itu siswa juga tidak paham mengenai peraturan permainan kippers, hal tersebut di 
karenakan pembelajaran kippers jarang di lakukan.

\section{Pelaksanaan}

proses

pembelajaran permainan disekolah, pada umunya siswa diberikan pemaparan teori dan latihan-latihan teknik dasar secara terpisah - pisah. Begitu pula dalam pembelajaran permainan bola kecil seperti dalam permainan kippers, siswa diintruksikan untuk melakukan gerakan teknik dasar menangkap, melempar dan memukul. Setelah berlatih teknik-teknik dasar tersebut kemudian diberikan penjelasan mengenai peraturan permainan. Selanjutnya pada pelaksanaan permainan kippers, dengan mencari tempat luas terlebih dahulu yang dapat digunakan untuk melaksanakan permainan tersebut.

Berdasarkan hasil pengamatan dalam proses pembelajaran permainan kippers yang dilakukan terhadap para siswa kelas IVB SD Negeri Bratan 1 No.71 Kota Surakarta terdapat beberapa siswa yang terlihat keterampilanya kurang maksimal dalam melakukan belajar tentang permainan kippers. Dalam pembelajaran permainan kippers guru masih menggunakan sarana seadanya, yaitu tiang hinggap yang digunakan menggunakan matras persegi dengan ukuran 50x50. Tinggi tiang hinggap tersebut juga sangat tidak relevan bagi permainan kippers, karena ketinggianya hanya 1 cm sehingga tidak terlihat oleh siswa dari kejauhan.

Alat-alat untuk pembelajaran permainan kippers menggunakan alat yang asli, misalkan pemukul. Alat pemukul yang asli memang tidak sesuai apabila digunakan siswa Sekolah Dasar karena permukaan penampang sangat sempit yang menyebabkan siswa saat memukul sering tidak mengenai bola. Alat pemukul asli mempunyai massa yang sangat berat, siswa sangat keberatan dengan alat pemukul asli. Hal tersebut tentu saja mengakibatkan hasil belajar siswa dalam pembelajaran gerak dasar permainan kippers rendah serta tidak memenuhi standart nilai KKM (Kriteria Kelulusan Minimal). Dengan jumlah keseluruhan siswa kelas IVB SD Negeri Bratan 1 No.71 Kota Surakarta adalah sebanyak 36 siswa yang terdiri dari 19 putra dan 17 
putri. Dengan kondisi awal (observasi pra penelitian) $33,33 \%$ (12 siswa) tergolong dalam katergori tuntas, sedangkan $66,67 \%$ (24 siswa) berada dalam kategori belum tuntas.

Berdasarkan permasalahanpermasalahan diatas agar siswa dapat meningkatkan hasil belajar permainan kippers salah satunya adalah dengan menggunakan penerapan modifikasi permainan kippers. Dengan adanya media pembelajaran sebagai alat pembelajaran diharapkan siswa dapat lebih mudah menerima dan menguasai materi sehingga tujuan dari pembelajaran tersebut dapat tercapai dengan baik. Oleh karena itu, maka peneliti ingin melakukan Penelitian Tindakan Kelas (PTK) dengan judul "Peningkatan Hasil Belajar Gerak Dasar Permainan Kippers Melalui Modifikasi Alat Pembelajaran pada Siswa Kelas IVB SD Negeri Bratan 1 No.71 Surakarta Tahun Ajaran 2016/2017".

\section{METODE}

Metode penelitian yang digunakan adalah Penelitian
Tindakan Kelas. Subjek yang diteliti dalam Penelitian Tindakan Kelas (PTK) ini adalah semua siswa kelas IV B SDN Bratan 1 Surakarta tahun 2016/2017, dengan jumlah 36 siswa, putra 19 siswa dan putri 17 siswa.

Teknik pengumpulan data dalam Penelitian Tindakan Kelas ini terdiri atas: tes dan observasi. Tes dipergunakan untuk mendapatkan data tentang hasil belajar servis atas bolavoli yang dilakukan oleh siswa..

Observasi, digunakan sebagai teknik untuk mengumpulkan data tentang aktivitas siswa dan guru selama kegiatan pembelajaran.

\section{HASIL DAN PEMBAHASAN}

Hasil belajar siswa dalam pembelajaran belajar gerak dasar permainan kippers setelah tindakan siklus I dilakukan menunjukkan hasil bahwa yang mencapai kriteria ketuntasan yaitu 55,6\% atau 20 siswa. Sesuai dengan KKM sekolah untuk pendidikan Jasmani di SD Negeri Bratan 1 No.71 Surakarta yaitu 75. Dalam hal ini sejumlah 20 siswa telah masuk dalam kriteria Tuntas sedangkan 16 siswa Tidak Tuntas. 
Berdasarkan hasil pelaksanaan pada data awal, siklus 1, dan siklus 2 dapat ditarik kesimpulan bahwa terjadi peningkatan hasil belajar bermain kippers pada siswa kelas IVB SD Negeri Bratan 1 No.71 Surakarta Tahun Ajaran 2016/2017. Dari hasil analisis yang diperoleh peningkatan yang signifikan terjadi pada prasiklus ke siklus I dan dari siklus I ke siklus II. Pada prasiklus hasil belajar belajar gerak dasar bermain kippers pada kategori baik sekali $0 \%$, baik 5,6\%, cukup 27,8\%, kurang 52,8\%, kurang sekali 13,9\% jumlah siswa yang tuntas adalah 12 siswa dan 24 siswa tidak tuntas. Hal tersebut disebabkan karena guru belum menemukan model pembelajaran yang tepat untuk materi ajar permainan kippers, selama ini pembelajaran materi tersebut menggunakan sarana standar seperti bola tenis, pemukul berpenampang asli, tiang hinggap berupa matras persegi. Oleh sebab itu siswa merasa kesulitan ketika memukul bola, siswa juga kesulitan saat lari menuju tiang hinggap karena tiang hinggap tidak kelihatan dari kejauhan.
Kemudian

melalui penerapan modifikasi alat pembelajaran pada Siklus I merupakan media yang tepat untuk proses pembelajaran permainan. Dilihat dari hasil belajar belajar bermain kippers pada siklus I sudah menunjukan peningkatan dengan kategori baik sekali sebesar 0,0\%, baik $25,0 \%$, cukup $27,8 \%$ kurang $38,9 \%$, kurang sekali $8,3 \%$ jumlah siswa yang tuntas adalah 20 siswa dan belum tuntas 16 siswa. Pemahaman siswa tentang materi dan antusias dalam mengikuti pembelajaran meningkat, siswa tidak merasa kesulitan dalam memukul bola.

Berdasarkan hasil refleksi dari Siklus I maka pada sikus II diberikan tambahan atau perbaikan dalam pembelajaran gerak dasar bermain kippers yaitu latihan melempar menangkap yang semula menggunakan bola plastik yang di isi kain lalu menggunakan bola tenis berekor. Formasinya pun diperbaiki yang semula lempar tanggap dengan teman yang didepanya kemudian diganti lempar tangkap dengan formasi melingkar. Selain itu 
memukul dan lari yang pada siklus 1 hanya melakukan saja tanpa permaninan, pada siklus 2 latihan memukul dan lari diterapkan dalam permainan dilapangan yang ukuran yang sudah dimodifikasi. waktu latihan keseluruhan pun ditambah guna memperoleh hasil belajar yang lebih baik dari siklus I sehingga mencapai target capaian yang diinginkan.

Hasil belajar bermain kippers pada siklus II menunjukan peningkatan dengan kategori baik sekali $0,0 \%$, baik 25,0\%, cukup $61,1 \%$, kurang $2,8 \%$, dan kurang sekali $1,1 \%$ dan hampir semua siswa telah memenuhi kreteria ketuntasan.

\section{SIMPULAN， IMPLIKASI DAN} SARAN

\section{Simpulan}

Penelitian Tindakan Kelas pada siswa kelas IVB SD Negeri Bratan 1 No.71 Surakarta Tahun Ajaran 2016/2017 dilaksanakan dalam 2 siklus. Setiap siklus terdiri dari empat tahapan, yaitu: (1) Perencanaan, (2) Pelaksanaan Tindakan, (3) Observasi Tindakan, dan (4) Analisis refleksi. Pada kondisi awal siswa yang tuntas 12 siswa atau $33,33 \%$ pada siklus 1 siswa yang tuntas 20 atau $55,56 \%$ dan pada siklus 2 siswa yang tuntas 31 atau $86,11 \%$. Berdasarkan analisis data yang telah dilakukan dan pembahasan yang telah dituangkan pada Bab IV, diperoleh simpulan bahwa:

Melalui modifikasi alat pembelajaran dapat meningkatkan hasil belajar permainan kippers pada siswa kelas IVB SD Negeri Bratan 1 No.71 Surakarta Tahun Ajaran 2016/2017. Hal ini terbukti dengan analisis data yang telah dilakukan bahwa terdapat peningkatan yang signifikan pada tiap-tiap siklus dan disetiap pertemuan ditiap siklus.

\section{Implikasi}

Keberhasilan dalam pemelitian tindakan kelas ini dipengaruhi oleh beberapa faktor. Faktor-faktor tersebut berasal dari guru, siswa, maupun dari kondisi lingkungan pembelajaran. Faktor dari pihak guru yang pandai dalam menyampaikan materi dan mengelola kelas dengan baik, dan pandai memilih metode pembelajaran yang 
tepat bagi siswa, modifikasi alat pembelajaran yang tepat ketika pembelajaran, penguasaan materi pada saat pembelajaran. Faktor dari siswa yaitu minat dan motivasi siswa dalam mengikuti proses pembelajaran.

Sedangkan faktor dari siswa adalah minat dan motivasi siswa yang tinggi dalam mengikuti pembelajaran. Melalui modifikasi alat pembelajaran yang sesuai dengan kondisi lingkungan dapat meningkatkan hasil belajar bermain kippers. Siswa menjadi tertarik dan siswa tidak lagi mengeluh kesulitan memukul karena sudah menggunakan pemukul penampang yang lebar selain itu siswa tidak lagi merasa kesulitan menuju tiang hinggap, karena tiang hinggap sudah menggunakan tiang yang tinggi dan menarik. Siswa juga merasa senang dalam pembalajaran karena menggunkan bola, tiang hinggap dan lapangan yang menarik sehingga tercipta proses pembelajaran yang lebih aktif, efektif, efisien, dan menyenangkan sehingga bisa mendukung suatu proses pembelajaran yang berkualitas.
Melalui modifikasi alat pembelajaran memberikan deskripsi yang nyata dapat meningkatkan hasil belajar bermain kippers pada siswa kelas IVB SD Negeri Bratan 1 No.71 Surakarta Tahun Ajaran 2016/2017. Sehingga penelitian ini dapat digunakan sebagai bahan pertimbangan bagi guru bidang studi pendidikan jasmani olahraga dan kesehatan untuk menerapkan modifikasi alat pembelajaran pada materi ajar lain.

Melalui penelitian ini juga menghapus anggapan bahwa pembelajaran permainan kippers merupakan permainan yang sulit dilakukan pada siswa kelas IV Sekolah Dasar.

\section{Saran}

Sehubungan dengan simpulan yang telah diambil dan implikasi yang ditimbulkan, disarankan hal-hal sebagai berikut khususnya pembelajaran materi gerak dasar permainan kippers SD Negeri Bratan 1 No.71 Surakarta:

1. Guru Penjasorkes harus memlih media yang tepat agar proses belajar mengajarnya dapat efektif 
efisien sehingga siswa senang dan gembira dalam mengikuti pembelajaran.

2. Dengan modifikasi alat pembelajaran terbukti dapat meningkatkan hasil belajar bermain kippers, sehingga guru hendaknya menerapkan modifikasi alat pembelajaran, karena dapat meningkatkan hasil belajar siswa dalam materi pembelajaran kippers.

3. Siswa yang belum tuntas senantiasa rajin mengikuti proses pembelajaran di sekolah dan jangan takut bermain kippers. 


\section{DAFTAR PUSTAKA}

Agus Kristyanto.2010. Penelitian Tindakan Kelas (PTK) Dalam Pendidikan Jasmani \& Kepelatihan Olahraga. Surakarta: UNS Press

Amung Ma'mun dan Yudha M. Saputra. (2000). Perkembangan Gerak dan Belajar Gerak. Departemen Pendidikan dan Kebudayaan.

Aunurrahman. (2012). Belajar dan Pembelajaran.Bandung: Alfabeta.

Dimyati \& Mudjiono. (2013). Belajar Dan Pembelajaran. Jakarta: Departemen Pendidikan Dan Kebudayaan.

DadanHeryana, GiriVerianti. 2010. Penjas Orkes kelas V. Jakarta: Pusat Perbukuan. Kementrian Pendidikan Nasional

Heryana Dadan, dkk. 2010. Pendidikan Jasmani Olahraga dan Kesehatan. Surakarta. CV. Putra Nugraha.

Hudrasta dan Yudha M. Saputra, (2000). Belajar Dan Pembelajaran. Jakarta: Departemen Pendidikan Nasional Direktorat Jendral Pendidikan Dasar dan Menengah

Imam Soejodi. (1979). Permainan dan Metodik. Jakarta: Departemen Pendidikan

Nasional Direktorat Jendral Pendidikan Dasar dan Menengah

Mahendra, A. \& Saputra, Y.M. (2006). Modul Perkembangan dan Belajar Motorik. Jakarta :Universitas Terbuka

Samsudin. (2008). Pembelajaran Pendidikan Jasmani Olahraga dan Kesehatan. Jakarta: Fajar Interpratama.

Slameto. (2010). Belajar dan Faktor - Faktor yang Mempengaruhi. Bandung: Rineka Cipta.

Thobroni, M \& Mustofa, A. (2011). Belajar dan Pembelajaran. Jogjakarta: ArRuzz Media. 